Document downloaded from:

http://hdl.handle.net/10251/65415

This paper must be cited as:

Luján, JM.; Climent, H.; Novella Rosa, R.; Rivas Perea, ME. (2015). Influence of a low pressure EGR loop on a gasoline turbocharged direct injection engine. Applied Thermal Engineering. 89:432-443. doi:10.1016/j.applthermaleng.2015.06.039.

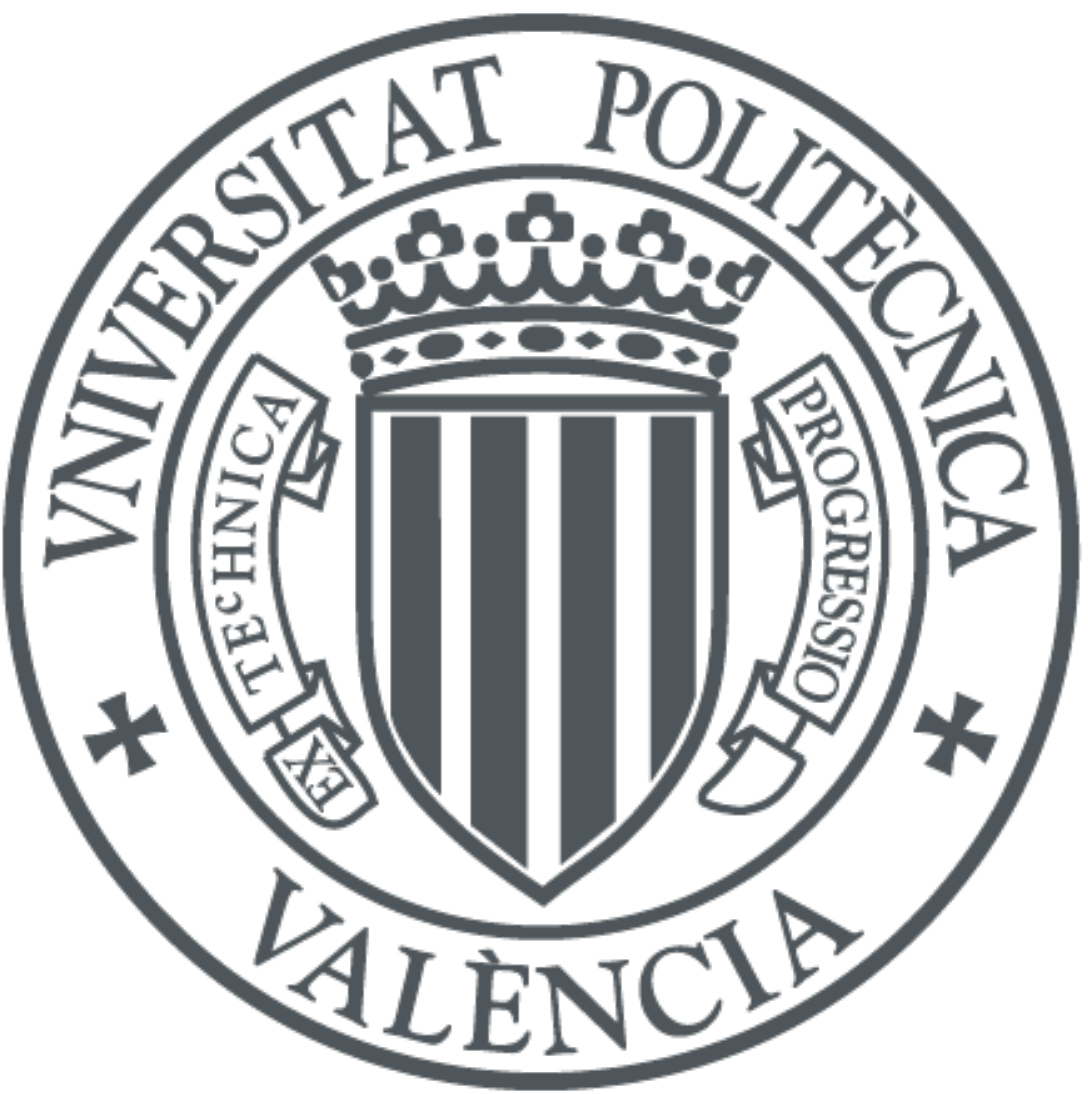

The final publication is available at

http://dx.doi.org/10.1016/j.applthermaleng.2015.06.039

Copyright Elsevier

Additional Information 


\title{
Influence of a low pressure EGR loop on a gasoline turbocharged direct injection engine
}

\author{
José Manuel Luján, Héctor Climent ${ }^{*}$, Ricardo Novella and Manuel Eduardo Rivas Perea \\ CMT Motores Térmicos, Universitat Politècnica de València, Spain \\ *Corresponding author: hcliment@mot.upv.es. Telephone: (+34) 9638776 50. Postal address: CMT \\ Motores Térmicos. Universitat Politècnica de València. Camino de Vera s/n. 46022. Valencia. Spain.
}

\begin{abstract}
This paper presents an experimental study of a low pressure EGR loop on a spark ignition (SI) Gasoline Turbocharged Direct Injection (GTDI) engine that will improve the understanding on the advantages and disadvantages of this strategy. Two steady engine operating conditions were investigated, 10 bar and 17 bar at $2000 \mathrm{rpm}$. At partial load conditions a combustion, performance, air management and exhaust gas emissions study was performed in order to analyses the EGR effect on the GTDI engine. The main advantages found were the reduction in fuel consumption due to the better combustion phasing, and the reduction in pumping losses and heat losses through the cylinder walls. A reduction on NOx, $\mathrm{CO}$ and soot was also observed when introducing EGR at these operating conditions. The main disadvantage found was the water condensation after the intercooler. At high load conditions similar analysis and conclusions to the partial load conditions are obtained. The EGR also allowed the combustion to be phased in a more efficient angle by reducing the risk of knocking, which helped reduce the exhaust gas temperature, despite the elimination of the fuel enrichment strategy. A reduction on $\mathrm{CO}$ and soot raw emissions was also observed when introducing EGR, as observed at partial load conditions, but a high reduction in NOx, CO, $\mathrm{HC}$ and soot emissions was observed after the catalyst since the fuel enrichment strategy is eliminated when cooled EGR is introduced. The main disadvantage found was the turbocharger limitation since higher compression ratio is required in order to keep the same air mass flow as the reference conditions without EGR. The original turbocharger is not designed to provide this higher compression ratio at low engine speed and high load. Results confirm how introducing EGR is a suitable strategy to control knocking and reduce simultaneously exhaust gas temperature and fuel consumption, but the disadvantages found in this investigation must be solved to assure its feasibility as a powerful technology to be implemented in future SI engines.
\end{abstract}

Keywords: SI engines, low pressure EGR loop, fuel consumption, turbocharging systems 


\section{Introduction}

The increasingly stringent pollutant emission regulations are leading the engine research to a low fuel consumption and low exhaust emissions era. SI engines are gaining attention since compression ignition (Cl) engines are struggling with the upcoming pollutant emission regulations. In the last decade, great research and development efforts are being carried out to design more efficient SI engines in terms of fuel consumption and production costs, while exhaust emissions are already under control by means of the well-known three-way catalyst technology.

An attractive strategy to reduce fuel consumption on SI engines consists of downsized engines with direct injection systems, where the displacement decreases and a turbocharging system compensates this loss of engine size, so the new engine configuration delivers the same torque and power as the reference engine, showed in more detail in these reference [1-3]. This SI engine technology reduces the fuel consumption by increasing the compression ratio and specific heats of the working fluids, and also by reducing the pumping and friction losses as described by Coltman et al. [4].

Another interesting strategy used to reduce fuel consumption in the SI research area is the introduction of cooled exhaust gas recirculation (EGR) as described by Vítek et al. and Wei et al. in their research work $[5,6]$. The EGR reduces the knocking tendency, the pumping losses, the exhaust gas temperature and the heat losses through the cylinder walls. It has been reported how introducing in some cases just $5 \%$ to $10 \%$ of cooled EGR at high loads avoids the need of operating the engine in rich fuel-to-air ratio conditions (fuel enrichment strategy) to control the exhaust gas temperature as observed by Bandel et al. in their research work [7].

Some studies confirmed the EGR influence as a good method to reduce fuel consumption. Grandin et al. [8] evaluated the knock suppression in a turbocharged SI engine by using cooled EGR. They found considerable knock suppression at maximum power output comparable with what was achieved with fuel enrichment. Cairns et al. [9] studied the reduction in fuel consumption at partial and high load using cooled EGR and found a reduction in fuel consumption at partial load of $3 \%$ and at high load around $17 \%$. Potteau et al. [10] focused their research on the potential of cooled EGR to reduce knocking and fuel consumption evaluating a high pressure (HP) and a low pressure (LP) EGR configuration. They found a considerable improvement in fuel consumption at partial and high load, noticing a significant advantage of the LP EGR system in comparison to the HP EGR system. Kumano et al. [11] also followed the same line of research on knocking suppression combining simulation and testing activities, quantifying in a $0.3 \%$ of fuel consumption reduction per $1 \%$ of EGR added. Alger et al. [12] reported the synergy between cooled EGR and GDI technologies obtaining reduction in fuel consumption of $4 \%$ in low and partial load primary through the reduction in pumping losses and $15 \%-20 \%$ at high load due to the improvement of combustion phasing, which is the time where the combustion process takes place in the engine cycle, and fuel enrichment elimination. Cairns et al. [13] evaluated different cooled EGR loop configurations and their advantages and disadvantages, and Zhong et al. [14] also discussed about different cooled EGR systems in a turbocharged SI engine. They found that the LP EGR system was the best configuration to ensure EGR operation in the entire engine operating range in order to minimize fuel consumption and exhaust gas emissions. Other more specific studies have been performed by Bourhis et al. [15] analyzing the compromise between cooled EGR and IGR in a GDI engine, showing that the IGR must be reduced as much as possible in order to maximize the cooled EGR effects: a reduction in fuel consumption and in knocking tendency, at partial and high loads. Gukelberger et al. [16] investigated the EGR dilution and 
fuel's effects on the spark plug temperature. They found that at partial load conditions the spark plug temperature was reduced by the introduction of cooled EGR but at high load conditions the spark plug temperature increased due to the better combustion phasing and the elimination of the fuel enrichment. Mingzhang et al. [17] studied the EGR effect on the cycle to cycle variation on a port fuel injection (PFI) engine finding that an increase of the EGR rate increases the cycle to cycle variation.

These previous investigations encourage further research efforts to gain knowledge on the real potential of cooled EGR for being standardized in future SI GTDI engines, and particularly, in its LP EGR loop configuration where the effects of the EGR can be maximized compared to the mixed and HP EGR loop configuration, as found by Takaki et al. [18].

In this framework, the research work focuses on a detailed evaluation and discussion of the impact of a LP EGR loop installed in a SI GTDI engine, analyzing the advantages and disadvantages of this EGR loop architecture. The experimental facility consists of a SI GTDI 2.0l 4-stroke 4-cylinder engine equipped with a custom LP EGR loop designed to provide the flexibility needed for carrying out the reported research activities. Theoretical tools, such as an advanced combustion diagnostic model, were combined in synergy with dyno test cell experiments to improve the understanding of the different trends observed. The discussion of results includes the analysis of the cylinder gas thermodynamic evolution, exhaust pollutant emissions, engine efficiency, and finally the turbocharger requirements and performance.

The paper is structured as follows. Section 2 is devoted to the experimental setup and the explanation of the theoretical tools. Section 3 contains the results and analysis of the EGR effects on the GTDI engine. And finally the main conclusions are presented in section 4.

\section{Experimental and theoretical tools}

\subsection{Experimental setup}

The experimental research activities were performed in a 4-stroke 4-cylinder 2.0 I direct injection turbocharged SI engine, whose key features are included in Table 1. The original ignition and air loop systems were kept for performing the tests. The engine was also equipped with a custom LP EGR system, extracting the exhaust gas flow downstream the catalyst outlet and introducing it before the compressor inlet. An EGR cooler was mandatory to prevent excessive temperatures on the EGR valve and compressor inlet. In addition, a back-pressure valve placed downstream the EGR extraction was used when higher EGR rates were needed. A detailed sketch of the engine layout, flow connections together with the measurement devices used in the study is shown in Figure 1.

The engine was fully instrumented and installed in a dynamic test bench. The cylinder pressure was measured using a Kistler 6961A250 piezoelectric type transducer and sampled with constant angular frequency. As usual for SI engines, an average of 100 cycles was recorded in order to analyze a suitable averaged cylinder pressure profile, reducing the uncertainties introduced by the cycle-to-cycle dispersion. The intake $\mathrm{CO}_{2}$ concentration and exhaust gas emissions ( $\mathrm{NOx}, \mathrm{HC}, \mathrm{CO}, \mathrm{CO}_{2}$ and $\mathrm{O}_{2}$ ) were measured with a Horiba Mexa 7100 DEGR. Exhaust emissions were measured in both upstream and downstream catalyst locations to check the device efficiency. Intake and exhaust $\mathrm{CO}_{2}$ concentrations were measured with a non-dispersive infrared analyzer (NDIR), while exhaust NOx concentration was measured by means of heated chemiluminiscent detector (HCLD). The EGR rate was obtained experimentally from the $\mathrm{CO}_{2}$ measurements in exhaust and intake manifold according to the expression used by Payri et al. [19]: 


$$
\text { EGRrate }=\frac{\left[\mathrm{CO}_{2}\right]_{\text {Intake }}-\left[\mathrm{CO}_{2}\right]_{\text {Ambient }}}{\left[\mathrm{CO}_{2}\right]_{\text {Exhaust }}-\left[\mathrm{CO}_{2}\right]_{\text {Ambient }}}
$$

Soot was measured using a HORIBA-1230PM. According to Figure 2, it includes a TSI-DCS device for soot measurement. Soot is measured by a diffusion charger (DC). Sample is initially diluted with an ejector pump and soot concentration is calculated by measuring the electrical current of ions attached onto the surface of charged particles. If further details are required Bermudez et al. [20] applied the same measuring system to develop experimental correlations for transient soot measurement in diesel exhaust aerosol with light extinction, electrical mobility and diffusion charger sensor techniques.

The accuracy of the instrumentation used in the research work is presented in Table 2.

\subsection{Diagnostic of the combustion process}

From the experimental cylinder pressure profile, the heat release rate $(H R R)$ was calculated by means of a combustion diagnosis model, used by Lapuerta et al. in their research work to perform a estimation of mean thermodynamic properties of the gas in a Diesel engine using in-cylinder pressure measurements [21]. This model applies the first law of thermodynamics along the closed engine cycle, between intake valve closing and exhaust valve opening. It uses the state equation of ideal gas to calculate the mean gas temperature in the chamber.

The hypotheses of the combustion diagnosis model are: a) the pressure is uniform in the combustion chamber, which is valid when the fluid and flame propagation velocities are much smaller than sound speed; b) the fluid in the chamber is considered a mixture of three gases: air, fuel and burned gases; c) perfect gas behavior is assumed for the gas mixture; $d$ ) correlations based on the temperature are used to calculate sensible internal energy of the gas mixture; e) the internal energy is calculated considering the mean gas temperature, which is the hardest hypothesis since burned products are hotter than mean temperature at the start of combustion, even though later they become closer. Therefore, the first law of thermodynamics for a closed system can be reordered as follows:

$$
H R R=-p_{c} \mathrm{~d} V_{c}-\delta Q_{w}-m_{c} \mathrm{~d} u_{c}
$$

where $p_{c}, v_{c}, m_{c}$ and $u_{c}$ are the pressure, volume, mass and internal energy in the cylinder respectively. Along with the previous two basic equations, several sub-models are employed to estimate the blow-by flow, the instantaneous volume considering deformations in the combustion chamber, and the heat transfer and the corresponding wall temperatures. The instantaneous in-cylinder heat transfer is calculated as

$$
\frac{\delta Q_{w}}{\mathrm{~d} t}=h\left[\left(T_{c}-T_{\text {liner }}\right) A_{\text {liner }}+\left(T_{c}-T_{w, \text { piston }}\right) A_{\text {piston }}+\left(T_{c}-T_{w, c y l-h e a d}\right) A_{\text {cyl-head }}\right]
$$

where surface areas consist of the liner, the piston and the cylinder head, and wall temperatures and the heat transfer coefficient are calculated by means of empirical correlations [21].

An influence of measurement errors and estimated parameters, using the described combustion diagnosis model, was performed by Payri et al. in their research work [22], where a detailed explanation of the 
equations used in the combustion model can be seen. A most recent research work was also performed by Benajes et al. [23] using this model. In addition a global energy balance in a Diesel engine was performed, using this model, by Payri et al. in their research work [24] in which also the equations used in the combustion diagnosis model to perform this global energy balance are explained.

Using the heat release law and ignition angle, combustion parameters are obtained such as crank angle at $10 \%$ heat release (CA10), crank angle at $50 \%$ heat release (CA50), crank angle at $90 \%$ heat release (CA90) and combustion duration (CD). The combustion duration is calculated using:

$$
C D_{i}=C A 90_{i}-C A 10_{i}
$$

The effect of cooled EGR on the SI turbocharged direct injection gasoline engine is analyzed by using CA50, combustion duration, combustion temperature and ignition advance. With these four variables it is enough to understand the effect of the EGR on the system. CA10 and CA90 are redundant since the combustion duration, CA50 and ignition advance are presented.

\section{Results and analysis}

In this section the results and analysis of the two tested steady engine operating conditions are going to be presented. The first operating conditions at partial load, 10 bar BMEP and $2000 \mathrm{rpm}$, and the second at full load, 17 bar BMEP and $2000 \mathrm{rpm}$.

\subsection{Partial load tests:}

A parametric study was performed at $2000 \mathrm{rpm}$ and 10 bar. The EGR rate was varied from $0 \%$ to $15 \%$ at iso-air mass flow, and the ignition advance was optimized at the maximum best timing (MBT) value for the tests.

\subsubsection{Combustion and engine performance:}

The introduction of EGR up to $15 \%$ reduced the fuel consumption in $4.2 \%$ and increased the indicated efficiency in $2 \%$ as it can be seen in Figure $3 b$ where the indicated efficiency and the break specific fuel consumption are plotted for different EGR rates. A similar result was found by Potteau et al. in their research work [10], where a $3 \%$ of fuel consumption reduction was observed at partial load conditions. The evolution of the exhaust temperature downstream the turbine for different EGR rates can be seen in Figure 3a. The exhaust gas temperature was also reduced from $665^{\circ} \mathrm{C}$ to 620 ㅇ $\mathrm{C}$ using $15 \% \mathrm{EGR}$ rate. This reduction in the exhaust gas temperature is due to the reduction in the combustion temperature and the new advanced combustion phasing. In some cases, as it will be explained in more detail later, this exhaust gas temperature reduction could be also caused by mainly the combustion phasing and the increase of heat losses during the cycle. These EGR effects on the combustion are going to be explained in more detail later in this section.

Analyzing the 5\% EGR rate operating conditions, the ignition advance was still limited by knocking. An advance on the CA50 can be observed in Figure $4 \mathrm{~b}$ where the ignition advance was increased in 4.5 CAD, improving the combustion phase compared to the reference operating conditions in 2 CAD. The combustion duration increased, as can be seen in Figure 4a, due to the dilution effect of the EGR that reduces the oxygen concentration in the mixture decreasing its reactivity, also found by Grandin et al. in their research work [25]. The reduction of the combustion temperature is also due to the EGR dilution 
effect, reducing the heat losses through the walls of the cylinder during the cycle, as can be seen in Figure 5 a.

The knocking was not a limitation with $10 \%$ EGR rate allowing the CA50 to be placed at the optimum crank angle. A big improvement on the CA50 and combustion phase is observed in Figure $4 \mathrm{~b}$, where the ignition advance was increased in 7 CAD compared to the 5\% EGR operating conditions. On the other hand the combustion duration decreased, as can be seen in Figure 4a, despite the EGR dilution effect, due to the new combustion phasing and the development of the combustion in that new reduced volume. The turbulence is higher, in this new crank-angle phased combustion and the in-cylinder volume where the combustion process occurs is smaller, increasing the reactivity of the mixture. This is also supported by the increase in heat losses compared to the 5\% EGR operating conditions, as observed in Figure 5a, due to the higher turbulence during the combustion. For the same reason the combustion temperature rested almost at the same value as the 5\% EGR operating conditions and did not decrease as it was expected, as it is observed in Figure $5 \mathrm{~b}$. Between $5 \%$ and $10 \%$ EGR the observed exhaust gas temperature reduction, of more than $20^{\circ} \mathrm{C}$ observed in Figure $3 a$, is mainly due to the new combustion phasing, since the combustion temperature rest almost at the same value compared to the $5 \%$ EGR rate operating conditions. In addition the increase on the heat losses observed in Figure 5a between $5 \%$ and $10 \%$ EGR rate conditions also helped to reduce the exhaust gas temperature.

Furthermore on the $15 \%$ EGR rate operating conditions, the CA50 rested the same as with the $10 \%$ EGR rate conditions, since is the optimum combustion phasing, presented in Figure $4 \mathrm{~b}$. The combustion duration increased due to the EGR dilution effect, as can be seen in Figure 4a. And the heat losses were reduced compared to the $10 \%$ EGR rate conditions, due to the combustion temperature reduction, observed in Figure 5b.

The CoV of the indicated mean effective pressure (IMEP) was reduced in the $5 \%$ EGR and $10 \%$ EGR rate conditions, as can be seen in Figure 4a, due to the better combustion phasing compensating the EGR dilution effect. But with 15\% EGR rate, knowing that the optimum combustion phasing was already achieved with $10 \%$ EGR rate, no changes on the combustion phasing were made, which causes an increase in the CoV because of the lower combustion temperature and longer combustion. The EGR leads to a decrease of the mixture reactivity and therefore higher combustion instability when the CA50 is maintained at the same value.

In this partial load conditions the effect of knocking suppression and dilution effect due to the introduction of cooled EGR was observed. The CA50 was able to be fazed at the optimum crank angle, the heat losses were reduced and the exhaust gas temperature was also reduced without compromising the CoV of the IMEP at high EGR rates. The best configuration at this load is the $15 \%$ EGR rate operating conditions which reduces the fuel consumption in $4.2 \%$, the exhaust gas temperature in $45^{\circ} \mathrm{C}$ and keeps a low IMEP CoV of $1.5 \%$.

\subsubsection{Air management:}

In order to analyze the air management area, it must be known, that the tests were performed at iso-air mass flow, as stated before. In Figure 6 the intake pressure and turbocharger speed are plotted as a function of the EGR rate. The intake pressure increases as the EGR rate increase due to the increase in mass on the same intake volume. 
The compressor outlet pressure rested the same during the increase of the EGR rate, as can be observed in Figure 8b, while the intake pressure increased. The compressor outlet pressure was higher than the observed pressure in the intake manifold because the throttle valve was controlling the load of the engine at these operating conditions. This could be also controlled by opening the waste-gate and controlling the outlet compressor pressure and so the intake manifold pressure with the throttle valve fully open. However, if the steady operating condition is followed by a full load transient demand the turbocharger response will have more delay than having the waste-gate fully closed and controlling the intake pressure with the throttle valve as in this case.

The turbocharger speed increases as the EGR rate increased, since the total intake mass increases by adding more EGR, as depicted in Figure $6 \mathrm{~b}$. The compressor mass flow increased while the outlet compressor pressure rested at the same value, moving the operating point to the right of the compressor map as Figure $6 \mathrm{c}$ shows.

At the compressor inlet, three thermocouples were placed separated by 120 - downstream the connection of the EGR pipe, whose arrangement is depicted in Figure 7. One of the thermocouples, Thermocouple 2, is aligned to the EGR outlet. The main goal was to identify a potential non homogeneous distribution of the EGR with the fresh air at the compressor inlet. At Figure 8a an evolution of the compressor inlet temperature while increasing the EGR rate is plotted. The difference on the inlet temperature between the three thermocouples at low EGR rates are negligible but at $15 \%$ EGR rate the difference is bigger between Thermocouple 2 and the others, which certifies that EGR and air are not well mixed before entering the compressor. This could be a future compressor reliability problem as EGR rates and compressor compression ratios increase.

An increase of 25 mbar in the exhaust pressure is observed at the maximum tested EGR rate, as illustrated in Figure $9 \mathrm{~b}$. This increase is explained because the compressor maintains the compression ratio during the EGR rate increase; this would increase the total mass flow through the turbine, increasing the delta pressure at the turbine and therefore the pressure on the exhaust manifold.

Concerning the pumping losses, these were reduced in $22 \%$ compared to the reference operating conditions; the evolution is observed in Figure 9a. Despite the increase of $25 \mathrm{mbar}$ in the exhaust pressure, the reduction in the pumping losses is due to a larger increase in the intake pressure. The higher intake pressure value is achieved because of the EGR addition.

The pumping losses also helped to reduce the fuel consumption in conjunction with the new combustion phasing and heat losses reduction explained before on the combustion and performance section. The $15 \%$ EGR rate operating conditions did not present a difficulty to the compressor at this engine load. The only disadvantage found was the water condensation after the intercooler that could obviously harm the engine if it is not treated correctly. The condensation appears since the air/EGR mixture temperature downstream the intercooler is below the dew point and water content in the exhaust gases condensates in the intake line.

\subsubsection{Exhaust raw emissions:}

In addition to the positive effects of EGR on the engine performance, it also had a beneficial effect on pollutant exhaust emissions. The behavior of the exhaust pollutant emissions for different EGR rates can be observed in Figure 10. As expected the EGR presence reduces the NOx emissions in almost $62 \%$. This 
reduction in NOx emissions is due to the reduction of the combustion temperature and in-cylinder oxygen concentration, reducing the formation of NOx. The HC emissions increased between the $5 \%$ and $15 \%$ EGR operating conditions in almost $62 \%$ because of the lower in-cylinder temperature and the longer combustion duration. At the 5\% EGR operating conditions, the $\mathrm{HC}$ emissions were reduced. Despite the reduction in the in-cylinder temperature, the combustion new phase compensate this phenomenon having also lower IMEP CoV compared to the reference point as was observed in Figure 4. The CO emissions were reduced in almost $13 \%$ using $15 \%$ of EGR rate, but for the $5 \%$ EGR and $10 \%$ EGR operating conditions a reduction of almost $44 \%$ was observed. This reduction in $\mathrm{CO}$ emissions is due to a reduction in the level of dissociation of $\mathrm{CO}_{2}$ because the flame temperature decreases due to the EGR dilution. The increase in CO emissions between the 10\% EGR and 15\% EGR rate is due to the worsened combustion process and instability caused by the EGR dilution, as presented in Figure 4a where the CoV tends to increase between these two operating points. The particulate matter (PM) emissions were also reduced because of the reduction on the combustion temperature, reducing the PM formation rate. Similar results were also presented by Alger et al. using a port fuel injection gasoline engine in their research work [26]. The evolution can be seen in Figure 10, where a decrease in concentration is observed as the EGR rate is increased. Between 10\% EGR and 15\% EGR the smallest size PM concentration almost rested at the same value, whether a reduction in the largest size PM concentration is observed.

In summary, the NOx, CO and PM emissions were reduced on the 15\% EGR rate operating conditions compared to the reference point. The increase in $\mathrm{HC}$ emissions do not represent a major problem since the three way catalyst (TWC) has over $98 \%$ of HC efficiency conversion, reducing the difference to $8 \mathrm{ppm}$ after the catalyst.

\subsection{Full load tests:}

Following the same methodology, a parametric study was performed at $2000 \mathrm{rpm}$ and 17 bar. The EGR rate was modified in a range from $0 \%$ to $14 \%$ at iso-air mass flow, and the ignition advance was optimized at the maximum best timing (MBT) value for the tests.

\subsubsection{Combustion and engine performance:}

This engine uses an fuel enrichment strategy at high load reference operating conditions in order to control the exhaust gas temperature. Introducing EGR allows the engine to operate in stoichiometric conditions with the straight positive impact on brake specific fuel consumption (BSFC). This was also observed by Bandel et al. [7], showing that with a small amount of EGR rate the fuel enrichment strategy can be eliminated at full load. According to Figure 11 a introducing $14 \%$ of EGR leads to a fuel consumption decreases of $22 \%$, also increasing in more than $4 \%$ the indicated efficiency compared to the reference operating conditions. Similar results were found by Potteau et al. in their research work [10], where a $17 \%$ of fuel consumption reduction was observed at full load conditions Figure $11 \mathrm{~b}$ shows how the exhaust gas temperature downstream the turbine decreases in almost $60^{\circ} \mathrm{C}$ using $14 \%$ of EGR compared to the reference operating conditions.

The observed reduction on the BSFC is higher than at partial load, due to the knocking limitation and fuel enrichment strategy at high load operating conditions, the room for improvement is bigger than at partial load. It must be taken into account that the reference operating condition at partial load almost had an indicated efficiency of $36 \%$ and at high load $32.5 \%$ which also certifies the statement mentioned before. 
These results are within the results found by Alger et al. [12], Cairns et al. [9] and Zhong et al. [14] in their research works.

Results included in Figure 11a confirm how a sharp fuel consumption reduction was achieved by introducing $4 \%$ of EGR due to the fuel enrichment elimination, maintaining the exhaust gas temperature at almost the same value as the reference operating conditions but operating in stoichiometric conditions. The combustion temperature remains at almost the same value as that of the reference conditions, as depicted in Figure 12a, so just a low reduction in heat losses is observed in Figure 12b. The data included in Figure 13 shows how, despite the 4\% EGR rate, the CA50 is improved in 1 CAD and the combustion duration is hardly affected as explained in the next paragraph.

The initial conditions for the combustion in the 4\% EGR rate case differs from the reference operating conditions in oxygen concentration, temperature and pressure. In the case of the reference conditions, the reactivity is decreased by the reduction of the cylinder temperature due to the vaporization of the extra injected fuel, this compensates the increase of reactivity because of the richer mixture and the increase in volumetric efficiency, improving the combustion phasing and reducing the combustion temperature, these effects can be seen in a study performed by Gurupatham et al. on rich flame propagation in SI engines [27]. In the 4\% EGR rate conditions, operating in stoichiometric conditions leads to a decreased in the vaporized fuel quantity compared to the reference point, which results in higher cylinder temperature at the onset of the combustion process and increases the reactivity of the mixture, but the EGR dilution effect compensates and finally leaves the combustion duration and knocking resistance similar to those of the reference point. Thus, this is the main reason for the observed similar exhaust gas temperature, combustion duration and combustion phasing.

Analyzing the $8 \%$ EGR and $12 \%$ EGR rate conditions, the same effects as those described for the $4 \%$ EGR case were observed and thus, the combustion duration tends to increase while increasing the EGR rate. The CoV also increases according to Figure 13a since the mixtures have less reactivity because of the EGR dilution effect, the cycle-to-cycle ignition consistency is negatively affected. The CA50 could be advanced, as it is observed in Figure $13 \mathrm{~b}$, because of the increase in knocking resistance. The combustion temperature decreases blocking the heat losses through the cylinder walls, as confirmed by Figure 12 . The exhaust gas temperature also drops while increasing the EGR rate because of the earlier combustion and the reduction of the combustion temperature as observed in Figure 11b.

Furthermore the 14\% EGR operating conditions shows the same behavior but with a higher improvement in the CA50, over 2 CAD, due to the higher knocking resistance at this EGR rate. The combustion duration increases and so the CoV compared to the other points, as shown in Figure 13. The heat losses are similar compared to the $12 \%$ EGR operating conditions. The low decrease in the combustion temperature, the longer combustion and new combustion phasing could explain the same heat losses compared to the $12 \%$ EGR operating conditions, as it can be observed in Figure 12. Looking at Figure 11b, the exhaust temperature also decreases compared to the $12 \%$ EGR operating point.

In this high load conditions the effect of knocking suppression and dilution effect due to the introduction of cooled EGR was also observed as in the partial load tests. The CA50 was able to be advance but was still limited by knocking at the maximum possible EGR rate. The heat losses were reduced compared to the reference operating conditions. The fuel enrichment strategy was eliminated by only using $4 \%$ of EGR rate without compromising the exhaust gas temperature. With higher EGR rate the exhaust gas temperature and fuel consumption was further reduced without compromising the CoV of the IMEP. The 
best results in terms of engine performance were provided by the $14 \%$ of EGR case, which reduces the fuel consumption by $22 \%$, the exhaust gas temperature in more than 50 으 and keeps an acceptable IMEP CoV of $2.5 \%$.

\subsubsection{Air management:}

The full load original operating condition for this engine is set at 19.5 bar. Due to the turbocharger limitations the tests were performed at 17 bar limiting the EGR rate to $14 \%$. At this engine load, the throttle valve is fully open and the only possibility to maintain iso-air mass flow while increasing the EGR rate is to increase the intake pressure by increasing the compression ratio of the compressor, this is achieved by closing the waste-gate valve on the turbine.

The intake pressure increases with the EGR rate as can be seen in Figure 14a. To achieve this intake pressure, the compression ratio of the compressor is also increased as seen in Figure 15a. While increasing the compression ratio, the turbocharger speed also increases as shown in Figure 14b, over $20 \%$ compared to the reference operating conditions. Compared to the partial load operating conditions, where the compression ratio of the compressor was not affected because of the throttle valve regulation, at full load a radical increase in the compression ratio is needed in order to maintain iso-air mass flow conditions while increasing the EGR rate.

The compressor operating conditions shifts in diagonal on the compressor map shown in Figure 15a. This explains the large increase on the turbocharger speed compared to the partial load operating conditions, where the compression ratio was the same during the EGR rate increase. On the other hand when analyzing the three thermocouples placed at the compressor inlet, it can be observed that increasing the EGR rate increases the difference between the thermocouple 2 (aligned with the EGR outlet) and the others. Similar results were seen at the partial load tests.

Furthermore the pumping losses increase with the EGR rate and the evolution is included in Figure 16a. The increase is more than $16 \%$ compared to the reference operating conditions. The increase is due to the higher compression ratio of the compressor, needing more power from the turbine and then increasing its delta pressure and finally the exhaust manifold pressure, as can be seen in Figure 16b.

Therefore, the pumping losses do not contribute to decrease the fuel consumption at this engine load conditions, so it is mainly caused by the new combustion phasing, fuel enrichment elimination and heat losses reduction. The $14 \%$ EGR rate presented a limitation to the turbocharger, because it was not possible to achieve the 19.5 bar at this engine speed with the original turbocharger. The other disadvantage found was the water condensation after the intercooler, as it was also observed on the partial load tests.

\subsubsection{Exhaust raw emissions:}

Before analyzing the exhaust pollutant emissions, it must be considered that the reference operating condition operates with a rich mixture. NOx emissions increases in Figure 17a between the reference point and the $4 \%$ EGR operating conditions, because it operates in stoichiometric conditions while the reference condition operates with a rich mixture, so the EGR case generates more suitable environment for NOx production despite the similar combustion temperature due to the higher oxygen concentration. After this EGR level, NOx emissions decrease while increasing the EGR rate until reaching the same concentration as the reference operating conditions with $14 \%$ of $E G R$. 
As expected HC emissions present an opposite behavior compared to NOx, as confirmed by Figure 17b, where $\mathrm{HC}$ decrease between the reference operating conditions and $4 \% E G R$, and then increase with the EGR. Switching from a rich mixture on the reference conditions to a stoichiometric mixture at the $4 \% \mathrm{EGR}$ operating conditions reduce the $\mathrm{HC}$ emissions. A richer mixture well over the stoichiometry always produces more $\mathrm{HC}$ emissions because of the lack of oxygen to burn the extra fuel. Later, from $4 \% \mathrm{EGR}$ in advance, an increase in $\mathrm{HC}$ emissions is observed while increasing the EGR rate because of the decrease in combustion temperature and the longer combustion duration.

Regarding the $\mathrm{CO}$ emissions, an important decrease can be seen in Figure 17c. The main reason is passing from a rich mixture to a stoichiometric mixture. Then, the reduction observed while increasing the EGR is due to more oxygen availability as a result of the less fuel injected. Also the main reason for the PM decrease between the reference conditions and the $4 \%$ EGR case is the elimination of the rich mixture. Then the decrease observed between $4 \%$ and $8 \%$ EGR cases is due to the decrease in the combustion temperature, reducing the PM formation rate. Similar results were also presented by Alger et al. using a port fuel injection gasoline engine in their research work [26]. However, the increase between the $8 \%$ and $14 \%$ EGR rate could be due to the decrease in oxygen concentration mixed with the cylinder lower temperatures, worsening the soot oxidation and finally increasing PM.

Introducing EGR in this engine load helps to operate in stoichiometric conditions, allowing the catalyst to work in the efficient range were a 98-99\% of conversion efficiency is achieved, improving the reference operating conditions catalyst efficiency, which is really low in the reference engine conditions because of the fuel enrichment strategy.

As a summary, CO and PM emissions decrease using 14\% EGR rate compared to the reference operating conditions. NOx emissions were kept at the same value as the reference point. And the increase in $\mathrm{HC}$ emissions do not represent a major problem since the three way catalyst (TWC) can operate in the maximum conversion efficiency range because of the stoichiometric mixture, improving all the after catalyst emissions in high percentages.

\section{Conclusions}

An experimental study on the potential of additive EGR in a turbocharged SI engine has been carried out following a parametrical approach, and the main conclusions extracted from this research work are included in this section.

The use of EGR has proved to decrease the specific fuel consumption and exhaust gas temperature, and to increase the knocking resistance of the mixture. The potential for simultaneously reducing NOx, $\mathrm{CO}$ and PM emissions has been also confirmed.

At partial load, the fuel consumption reduction is caused by the improvement on the combustion phasing and the reduction on heat and pumping losses. However, in certain cases, as it was seen for the $10 \%$ EGR operating conditions, the major improvement could come from the combustion phasing and the reduction in pumping losses. On exhaust emissions, NOx decrease is the result of the reduction in the oxygen concentration and combustion temperature as expected when using EGR. HC emissions increase because of the lower combustion temperatures and longer combustions, and $\mathrm{CO}$ and soot decrease for the same reason. On the air management side, no disadvantages were detected apart from the compressor inlet 
temperature difference when operating with high EGR rates, but at this engine load it is not a major problem for the compressor.

At high load, the reference test operates with a rich mixture to control the exhaust gas temperature. Introducing EGR permits the engine to operate with a stoichiometric mixture while maintaining the exhaust gas temperature under control, reducing the fuel consumption in a great percentage compare to the partial load tests. The fuel consumption reduction is due to the elimination of the fuel enrichment, the improvement of the combustion phasing and the reduction of heat losses. On the exhaust pollutant emissions, NOx were kept at the same value compared to the reference conditions. HC emissions increase and $\mathrm{CO}$ and PM emissions decrease as in the partial load tests. When introducing EGR the engine can operate in stoichiometric conditions and the three-way catalyst is able to operate in the efficient conversion range and largely reduce the emissions compared to the reference test operating with a rich mixture. On the other hand a real disadvantage was observed in the air management, where the turbocharger needs to be re-matched in order to achieve the same torque values as the original full load conditions. This could lead into smaller turbines, penalizing the maximum power and fuel consumption of the engine at high speeds. In the compressor inlet temperature the same problem as in partial load tests was detected, but for the compression ratio values seen in this operating condition does not represent a major problem. It could be a major problem for future downsized gasoline engines, where a higher demand on the compressor compression ratio is expected. The pumping losses in this operating conditions increase because of the higher exhaust pressure needed to increase the work produced by the turbine, leading to a higher turbine expansion ratio.

A major problem found operating with EGR was the water condensation on the intercooler, a problem that could damage the engine if it is not managed carefully. This problem was seen at partial and full load tests, and it is more noticeable in terms of liters per hour at the full load operating conditions as expected.

As a final remark, EGR is a powerful strategy to reduce fuel consumption, exhaust gas temperature, and NOx, $\mathrm{CO}$ and PM exhaust emissions, but the development of new turbocharged SI engines have to take into account several key aspects. Suitable turbocharging system matching is mandatory for achieving the low end torque desired values together with the required EGR rate and exhaust gas temperature at full load and low speed conditions. The proper homogeneity of the air and EGR mixture at the compressor inlet must be attained to maximize the benefits of the EGR strategy, while a purge system at the intercooler is needed to evacuate the condensate water and assure the engine integrity. 


\section{References}

[1] Lumsden G, OudeNijeweme D, Fraser N, Blaxill H. Development of a Turbocharged Direct Injection Downsizing Demonstrator Engine. SAE Technical Paper, (2009) 2009-01-1503, doi: 10.4271/2009-011503.

[2] Fraser N, Blaxill H, Lumsden G, Bassett M. Challenges for Increased Efficiency through Gasoline Engine Downsizing. SAE Int J Engines, 2 (2009), pp. 991-1008.

[3] Shahed SM, Bauer K-H. Parametric Studies of the Impact of Turbocharging on Gasoline Engine Downsizing. SAE Technical Paper, (2009) 2009-01-1472, doi: 10.4271/2009-01-1472.

[4] Coltman D, et al. Project Sabre: A Close-Spaced Direct Injection 3-Cylinder Engine with Synergistic Technologies to Achieve Low CO2 Output. SAE Int J Engines, 1 (2008), pp. 129-46.

[5] Vítek O, Macek J, Polášek M, Schmerbeck S, Kammerdiener T. Comparison of Different EGR Solutions. SAE Technical Paper, (2008) 2008-01-0206, doi: 10.4271/2008-01-0206.

[6] Wei H, Zhu T, Shu G, Tan L, Wang Y. Gasoline engine exhaust gas recirculation - A review. Applied Energy, 99 (2012), pp. 534-44.

[7] Bandel W, Fraidl GK, Kapus PE, Sikinger H, Cowland CN. The Turbocharged GDI Engine: Boosted Synergies for High Fuel Economy Plus Ultra-low Emission. SAE Technical Paper, (2006) 2006-01-1266, doi: 10.4271/2006-01-1266.

[8] Grandin B, Ångström H-E, Stålhammar P, Olofsson E. Knock Suppression in a Turbocharged SI Engine by Using Cooled EGR. SAE Technical Paper, (1998) 982476, doi: 10.4271/982476.

[9] Cairns A, Blaxill H, Irlam G. Exhaust Gas Recirculation for Improved Part and Full Load Fuel Economy in a Turbocharged Gasoline Engine. SAE Technical Paper, (2006) 2006-01-0047, doi: 10.4271/2006-01-0047.

[10] Potteau S, Lutz P, Leroux S, Moroz S, Tomas E. Cooled EGR for a Turbo SI Engine to Reduce Knocking and Fuel Consumption. SAE Technical Paper, (2007) 2007-01-3978, doi: 10.4271/2007-01-3978.

[11] Kumano K, Yamaoka S. Analysis of Knocking Suppression Effect of Cooled EGR in Turbo-Charged Gasoline Engine. SAE Technical Paper, (2014) 2014-01-1217, doi: 10.4271/2014-01-1217.

[12] Alger T, Chauvet T, Dimitrova Z. Synergies between High EGR Operation and GDI Systems. SAE Int J Engines, 1 (2008), pp. 101-14.

[13] Cairns A, Fraser N, Blaxill H. Pre Versus Post Compressor Supply of Cooled EGR for Full Load Fuel Economy in Turbocharged Gasoline Engines. SAE Technical Paper, (2008) 2008-01-0425, doi: 10.4271/2008-01-0425.

[14] Zhong L, Musial M, Reese R, Black G. EGR Systems Evaluation in Turbocharged Engines. SAE Technical Paper, (2013) 2013-01-0936, doi: 10.4271/2013-01-0936.

[15] Bourhis G, Chauvin J, Gautrot X, de Francqueville L. LP EGR and IGR Compromise on a GDI Engine at Middle Load. SAE Int J Engines, 6 (2013), pp. 67-77. 
[16] Gukelberger R, Alger T, Mangold B, Boehler J, Eiden C. Effects of EGR Dilution and Fuels on Spark Plug Temperatures in Gasoline Engines. SAE Int J Engines, 6 (2013), pp. 447-55.

[17] Pan M, Shu G, Wei H, Zhu T, Liang Y, Liu C. Effects of EGR, compression ratio and boost pressure on cyclic variation of PFI gasoline engine at WOT operation. Applied Thermal Engineering, 64 (2014), pp. 4918.

[18] Takaki D, Tsuchida H, Kobara T, Akagi M, Tsuyuki T, Nagamine M. Study of an EGR System for Downsizing Turbocharged Gasoline Engine to Improve Fuel Economy. SAE Technical Paper, (2014) 201401-1199, doi: 10.4271/2014-01-1199.

[19] Payri F, Lujan J, Climent H, Pla B. Effects of the Intake Charge Distribution in HSDI Engines. SAE Technical Paper, (2010) 2010-01-1119, doi: 10.4271/2010-01-1119.

[20] Vicente B, José VP, López JJ, Daniel C. Experimental correlations for transient soot measurement in diesel exhaust aerosol with light extinction, electrical mobility and diffusion charger sensor techniques. Measurement Science and Technology, 25 (2014), pp. 065204.

[21] Lapuerta M, Armas O, Hernández JJ. Diagnosis of DI Diesel combustion from in-cylinder pressure signal by estimation of mean thermodynamic properties of the gas. Applied Thermal Engineering, 19 (1999), pp. 513-29.

[22] Payri F, Molina S, Martín J, Armas O. Influence of measurement errors and estimated parameters on combustion diagnosis. Applied Thermal Engineering, 26 (2006), pp. 226-36.

[23] Benajes J, Olmeda P, Martín J, Carreño R. A new methodology for uncertainties characterization in combustion diagnosis and thermodynamic modelling. Applied Thermal Engineering, 71 (2014), pp. 38999.

[24] Payri F, Olmeda P, Martin J, Carreño R. A New Tool to Perform Global Energy Balances in DI Diesel Engines. SAE Int J Engines, 7 (2014), pp. 43-59.

[25] Grandin B, et al. Heat Release in the End-Gas Prior to Knock in Lean, Rich and Stoichiometric Mixtures With and Without EGR. SAE Technical Paper, 2002-01-0239 (2002). 10.4271/2002-01-0239.

[26] Alger T, Gingrich J, Khalek IA, Mangold B. The Role of EGR in PM Emissions from Gasoline Engines. SAE Int J Fuels Lubr, 3 (2010), pp. 85-98.

[27] Gurupatham A, Teraji A. A Study of Rich Flame Propagation in Gasoline SI Engine Based on 3-D Numerical Simulations. SAE Technical Paper, (2011) 2011-28-0125, doi: 10.4271/2011-28-0125.

[28] TSI 2006 Model 3090: engine exhaust particle sizer spectrometer. Operation and service manual (Shoreview, MN: TSI). 


\section{List of captions}

Table 1. Engine main characteristics.

Table 2. Instrumentation accuracy.

Figure 1. Engine test bench layout.

Figure 2. Engine exhaust particle sizer (courtesy of TSI) [28].

Figure 3. Engine performance parameters evolution for different EGR rates. (a) Exhaust manifold temperature. (b) Brake specific fuel consumption and indicated efficiency.

Figure 4. Combustion parameters variation for different EGR rates. (a) Combustion duration and CoV of the indicated mean effective pressure. (b) CA50 and ignition advance.

Figure 5. (a) Heat losses evolution with different EGR rates. (b) Combustion temperature variation for different EGR rates.

Figure 6. Air management parameters evolution for different EGR rates. (a) Intake pressure. (b) Turbocharger speed.

Figure 7. Thermocouples arrangement placed at the compressor inlet

Figure 8. (a) Compressor operating points. (b) Compressor inlet temperature evolution for different EGR rates. (c) Intake mass flow and outlet compressor pressure variation for different EGR rates.

Figure 9. Air management parameters evolution for different EGR rates. (a) Pumping losses. (b) Exhaust manifold pressure.

Figure 10. Exhaust emissions evolution for different EGR rates. (a) NOx. (b) HC. (c) CO. (d) Soot.

Figure 11. Engine performance parameters evolution for different EGR rates. (a) Brake specific fuel consumption and indicated efficiency. (b) Exhaust manifold temperature.

Figure 12. (a) Combustion temperature variation for different EGR rates. (b) Heat losses evolution for different EGR rates.

Figure 13. Combustion parameters variation for different EGR rates. (a) Combustion duration and CoV of the indicated mean effective pressure. (b) CA50 and ignition advance.

Figure 14. Air management parameters evolution for different EGR rates. (a) Intake pressure. (b) Turbocharger speed.

Figure 15. (a) Compressor operating points. (b) Compressor inlet temperature evolution for different EGR rates.

Figure 16. Air management parameters evolution for different EGR rates. (a) Pumping losses. (b) Exhaust manifold pressure.

Figure 17. Exhaust emissions evolution for different EGR rates. (a) NOx. (b) HC. (c) CO. (d) Soot. 



\begin{tabular}{|l|c|}
\hline Type & 4 stroke (-) \\
\hline Total displacement & $1999(\mathrm{~cm} 3)$ \\
\hline Bore & $87.5(\mathrm{~mm})$ \\
\hline Stroke & $83.1(\mathrm{~mm})$ \\
\hline $\begin{array}{l}\text { Number of } \\
\text { cylinders }\end{array}$ & $4(-)$ \\
\hline Valves per cylinder & $4(-)$ \\
\hline Compression Ratio & $10.2: 1$ \\
\hline Fuel system & Direct Injection \\
\hline Max. Power/speed & $143(\mathrm{~kW}) / 5000 \mathrm{rpm}$ \\
\hline Max Torque/speed & $310(\mathrm{Nm}) / 1750 \mathrm{rpm}$ \\
\hline
\end{tabular}

Table 1. Engine main characteristics 


\begin{tabular}{|l|l|l|}
\hline Sensor & Variable & Accuracy [\%] \\
\hline Piezoelectric & In-cylinder pressure & \pm 0.7 \\
\hline Thermocouples & Temperature of all fluids & \pm 0.35 \\
\hline Encoder & Engine speed & \pm 0.006 \\
\hline Exhaust gas analyzer & Exhaust emissions (NO$\left., \mathrm{CO}, \mathrm{HC}, \mathrm{O}_{2}\right)$ & \pm 2 \\
\hline PM meter & PM (Soot concentration, particle diameter) & \pm 2 \\
\hline Torque meter & Torque & \pm 0.1 \\
\hline Fuel mass flow meter & Fuel mass flow & \pm 0.2 \\
\hline Air mass flow meter & Air mass flow & \pm 0.12 \\
\hline
\end{tabular}

Table 2. Instrumentation accuracy 


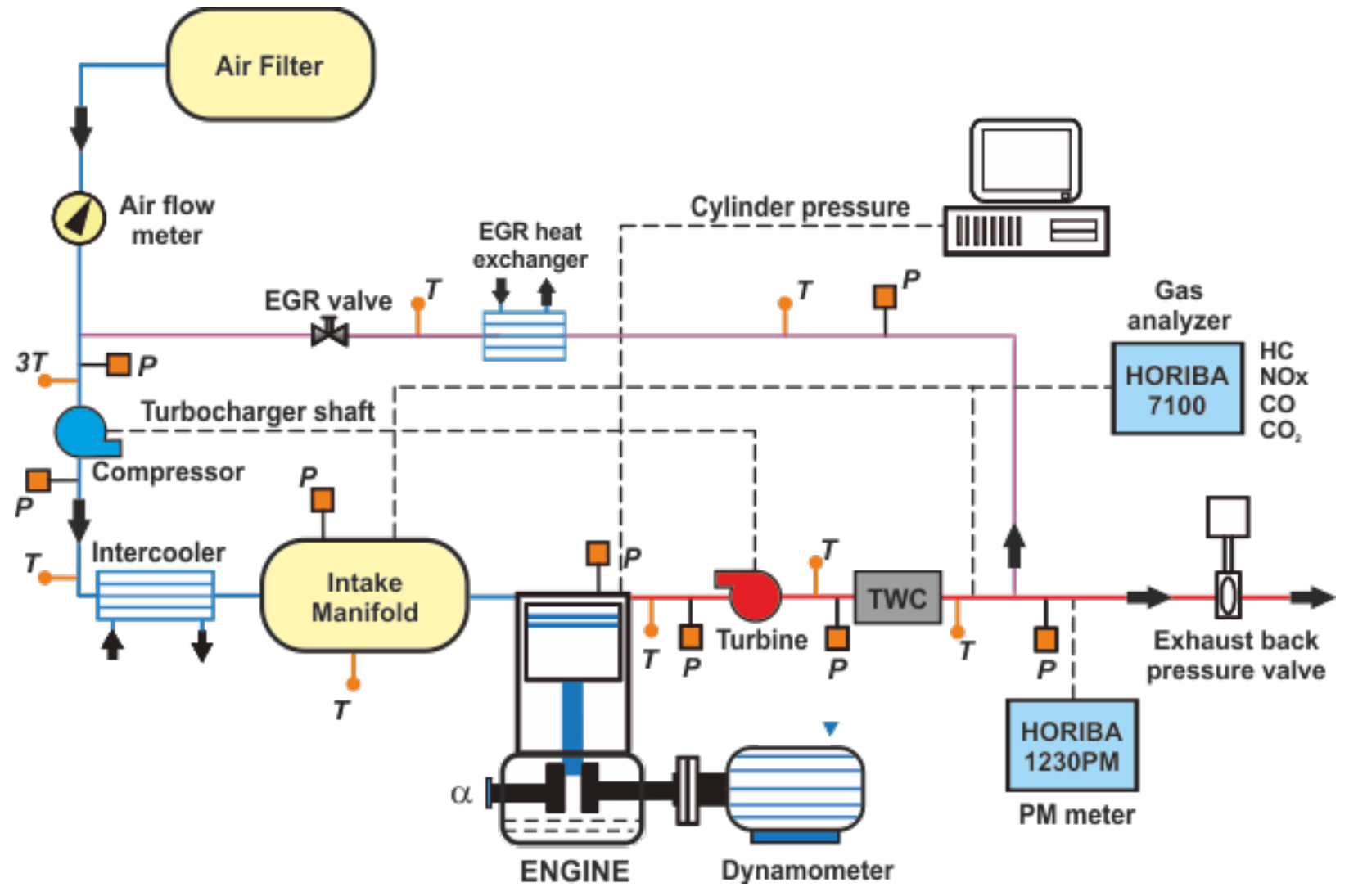

Figure 1. Engine test bench layout 


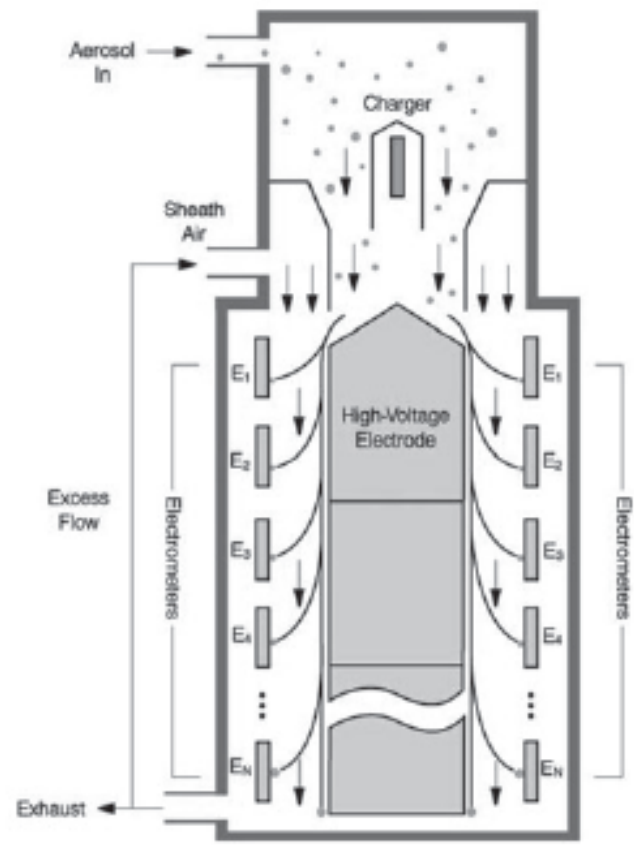

Figure 2. Engine exhaust particle sizer (courtesy of TSI) [28] 

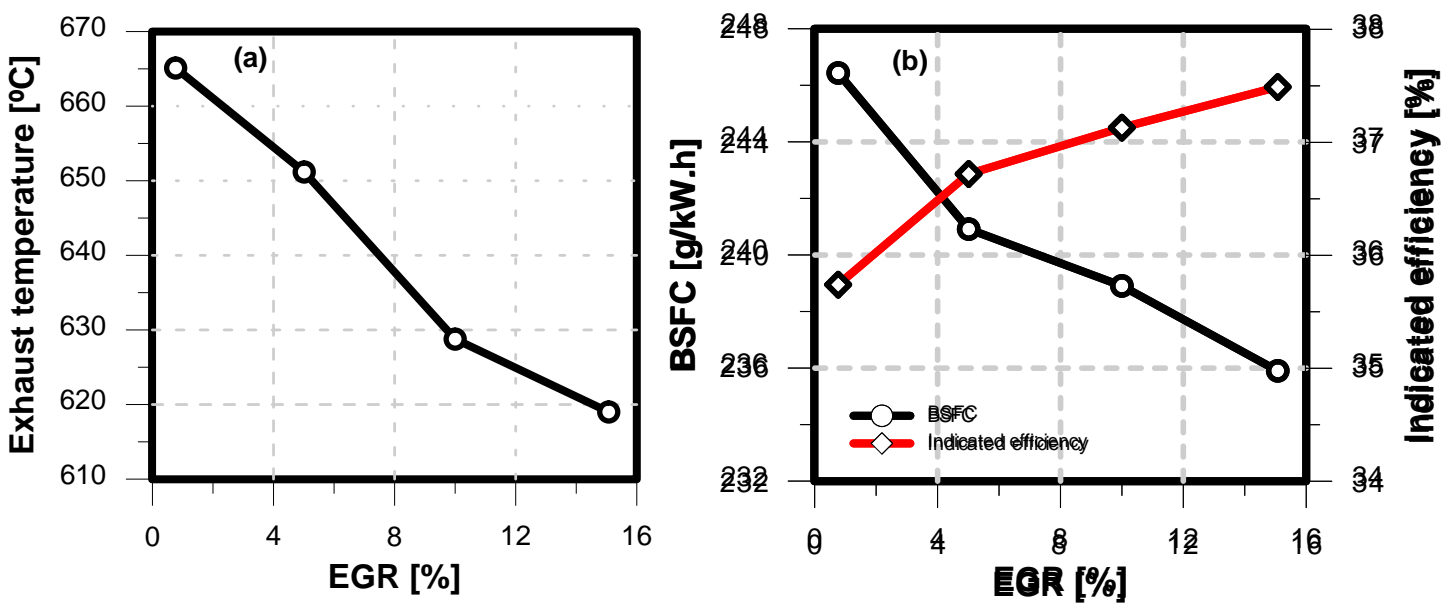

Figure 3. Engine performance parameters evolution for different EGR rates. (a) Exhaust manifold temperature. (b) Brake specific fuel consumption and indicated efficiency 

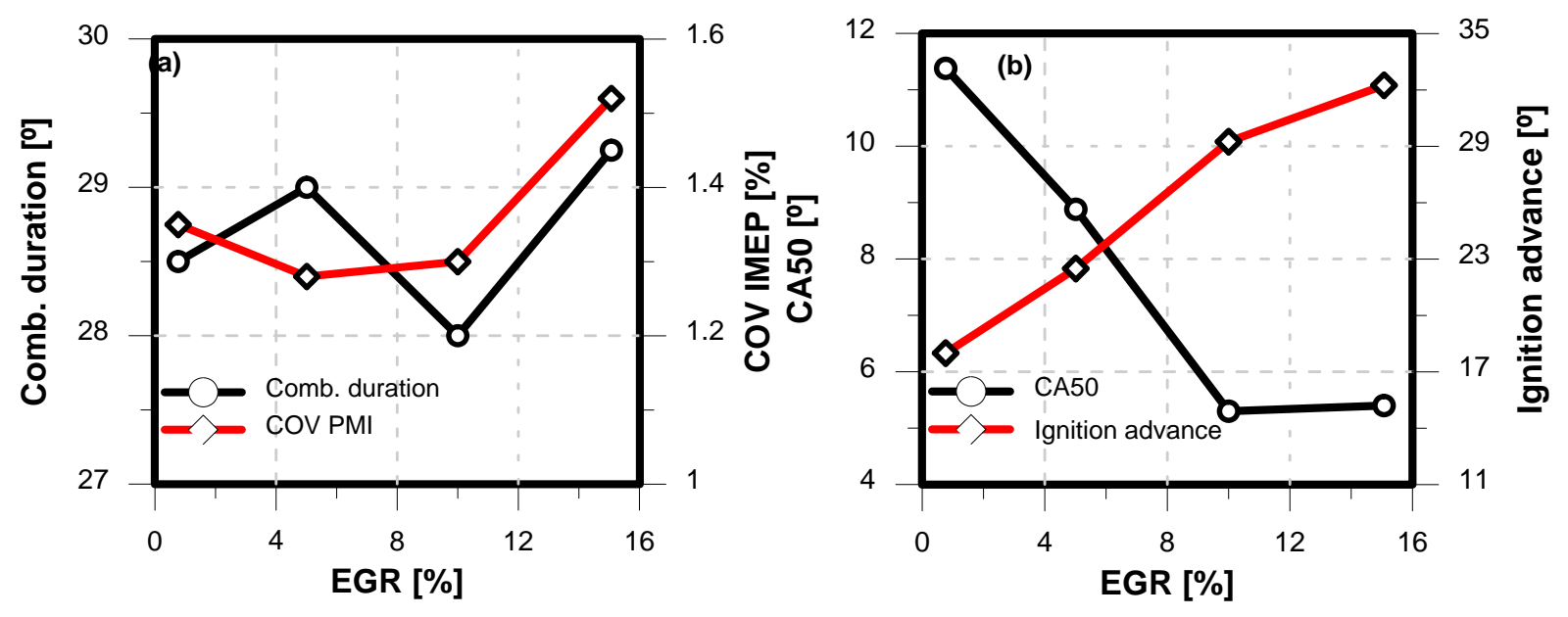

Figure 4. Combustion parameters variation for different EGR rates. (a) Combustion duration and CoV of the indicated mean effective pressure. (b) CA5O and ignition advance 

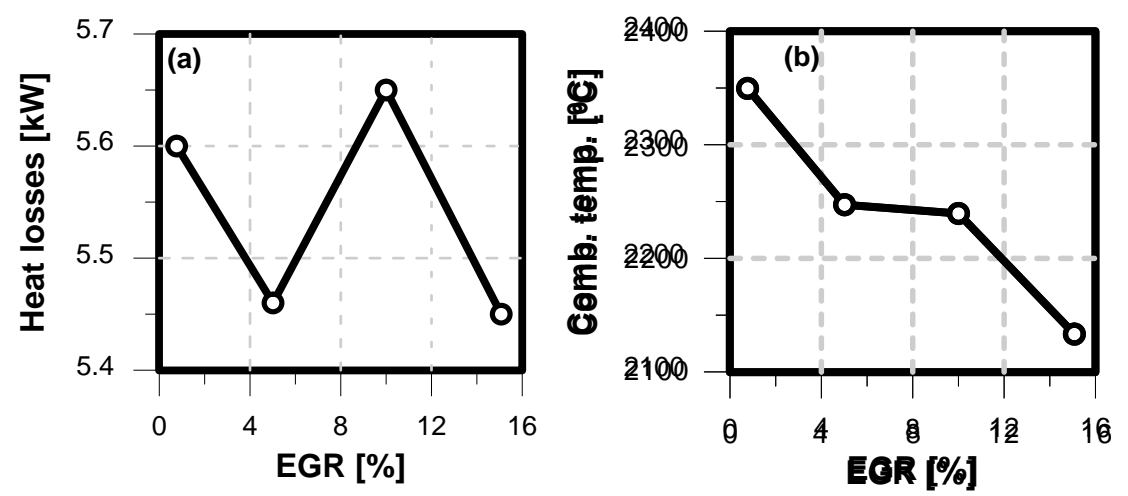

Figure 5. (a) Heat losses evolution with different EGR rates. (b) Combustion temperature variation for different EGR rates 

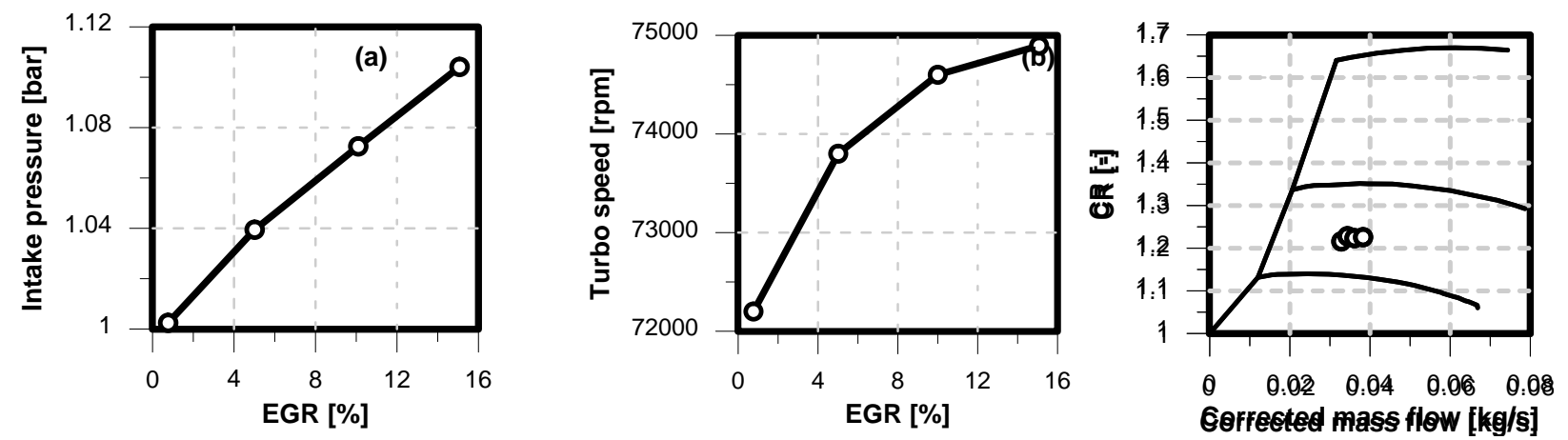

Figure 6. Air management parameters evolution for different EGR rates. (a) Intake pressure. (b) Turbocharger speed. (c) Compressor operating points. 


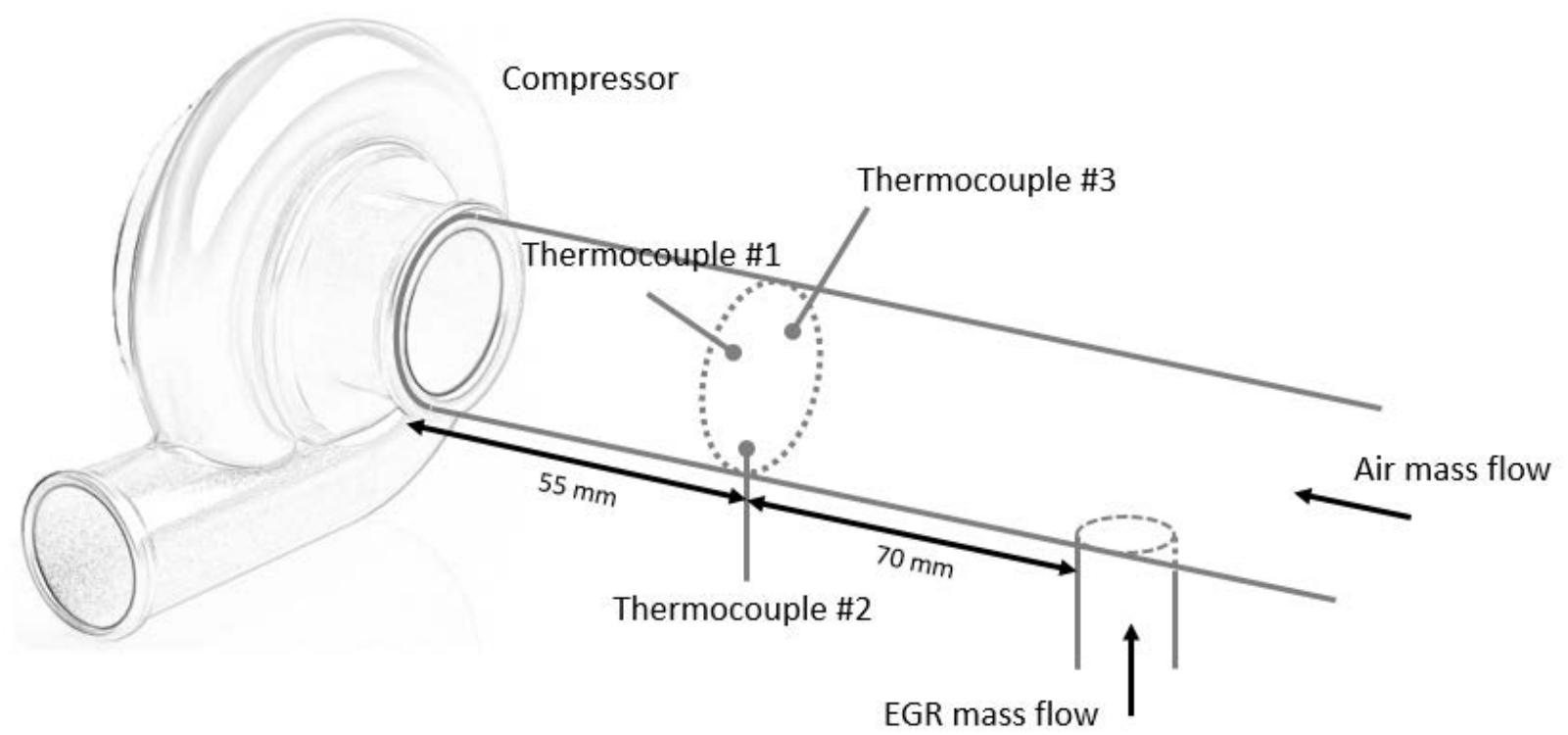

Figure 7. Thermocouples arrangement placed at the compressor inlet 

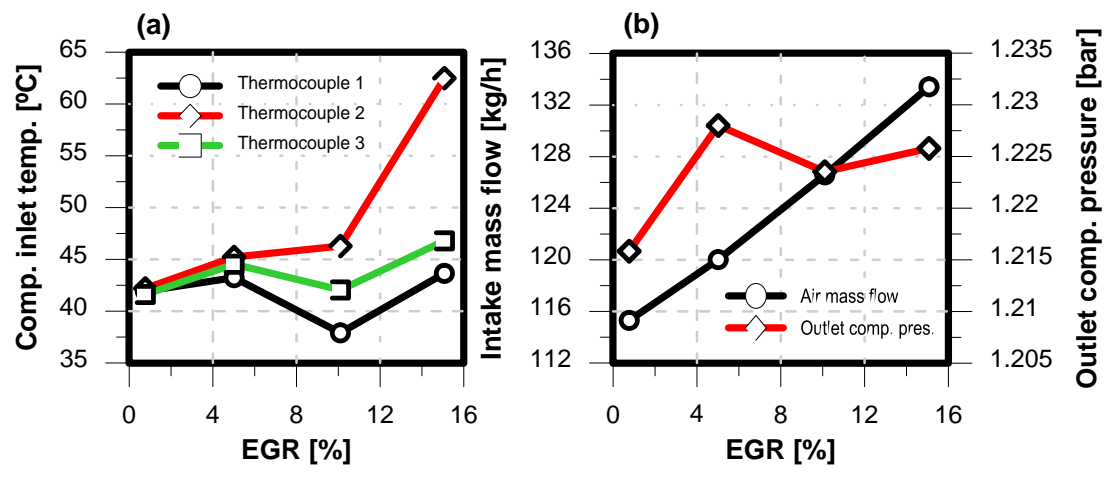

Figure 8. (a) Compressor inlet temperature evolution for different EGR rates. (b) Intake mass flow and outlet compressor pressure variation for different EGR rates 

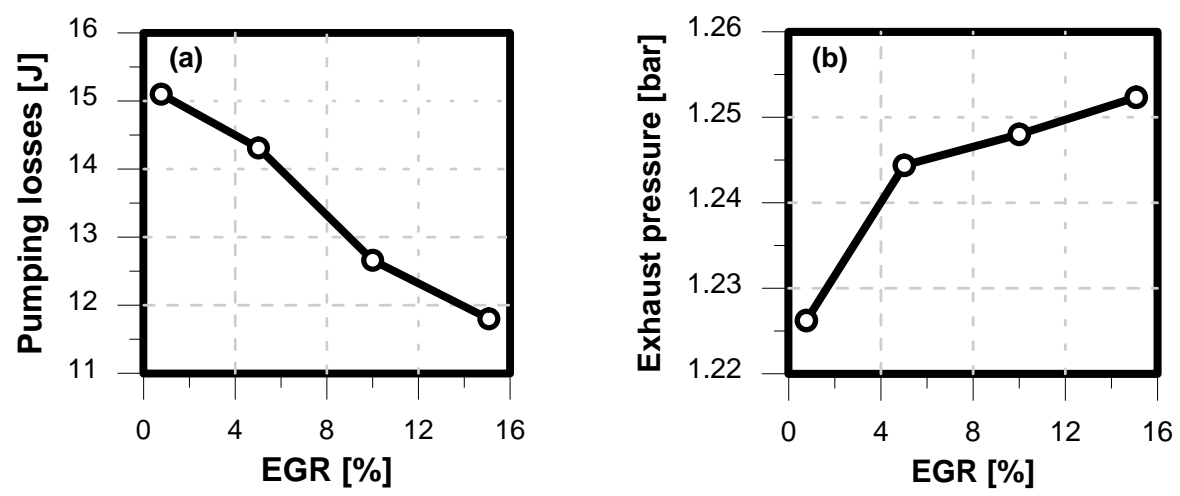

Figure 9. Air management parameters evolution for different EGR rates. (a) Pumping losses. (b) Exhaust manifold pressure 

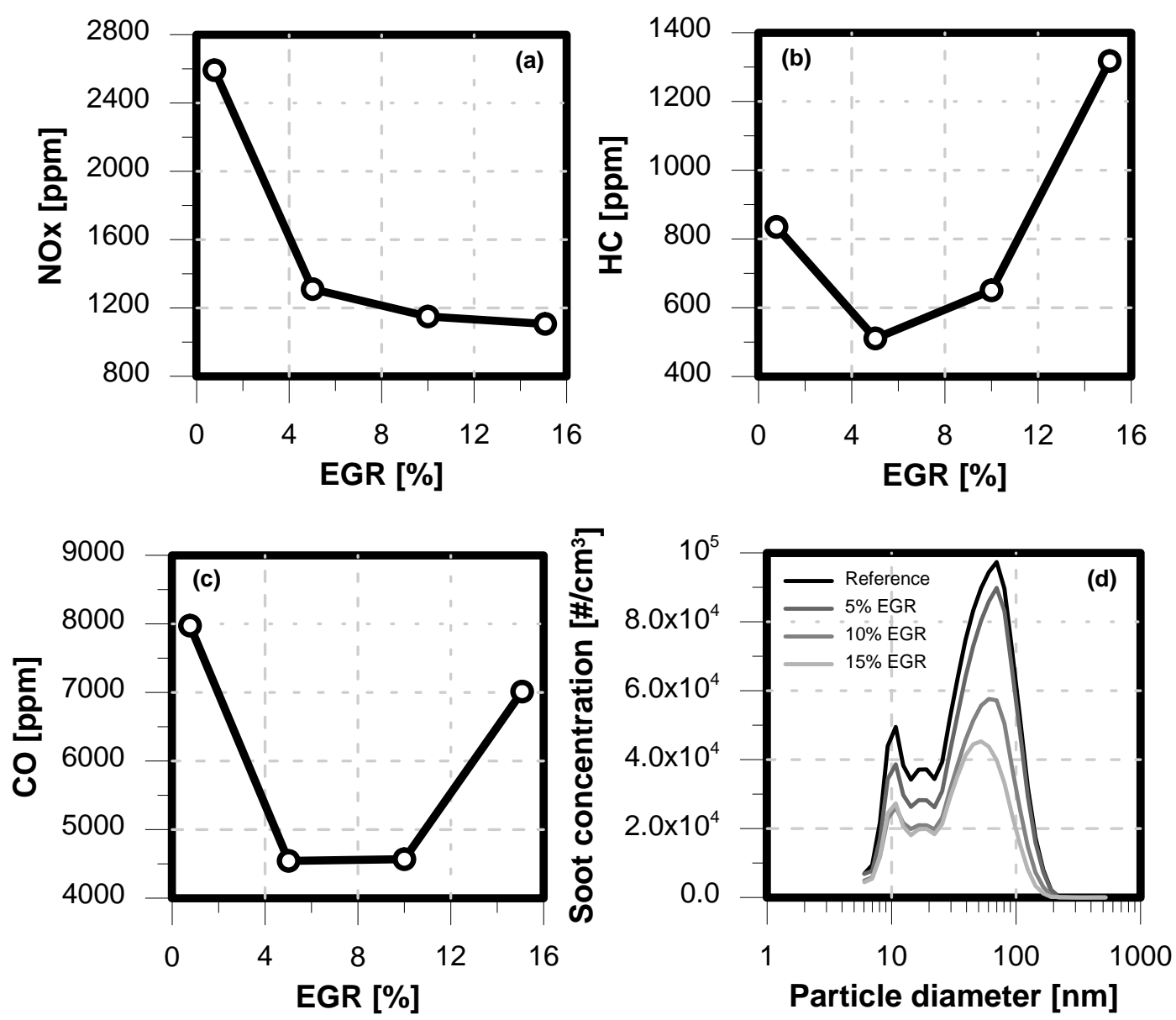

Figure 10. Exhaust emissions evolution for different EGR rates. (a) NOx. (b) HC. (c) CO. (d) Soot 

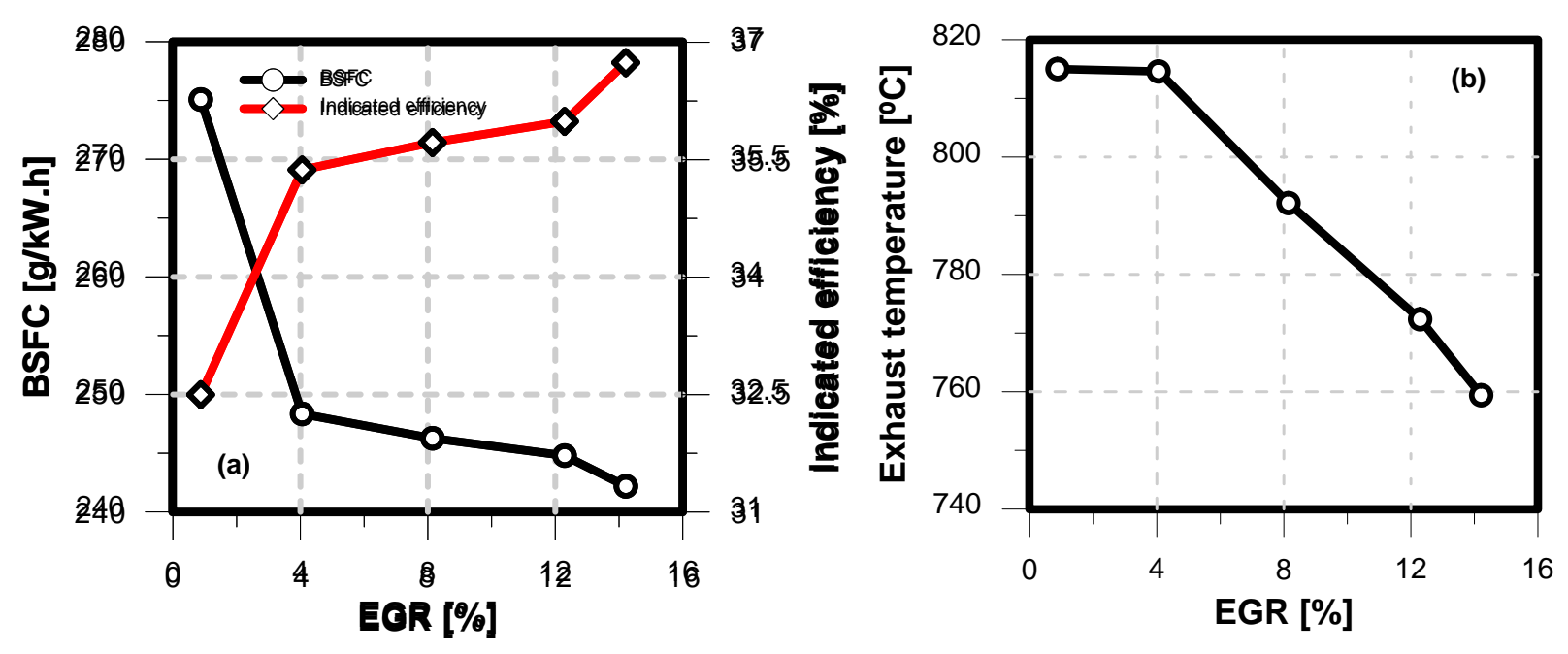

Figure 11. Engine performance parameters evolution for different EGR rates. (a) Brake specific fuel consumption and indicated efficiency. (b) Exhaust manifold temperature 

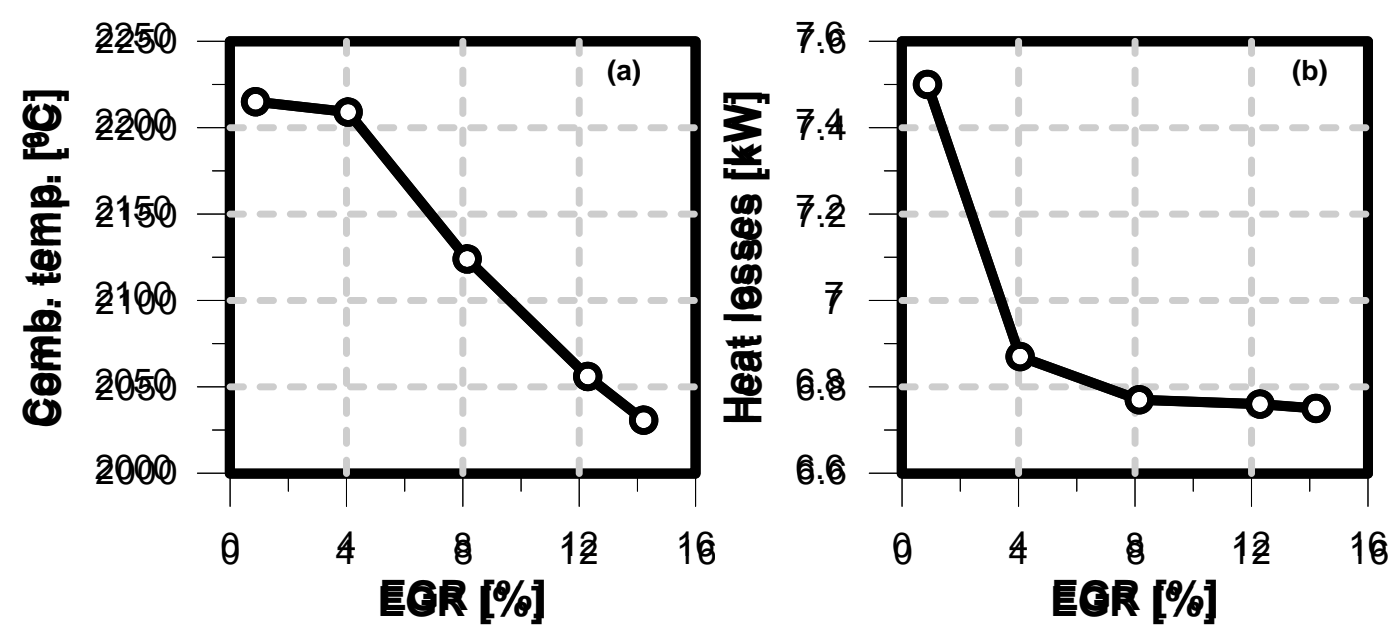

Figure 12. (a) Combustion temperature variation for different EGR rates. (b) Heat losses evolution for different $E G R$ rates 

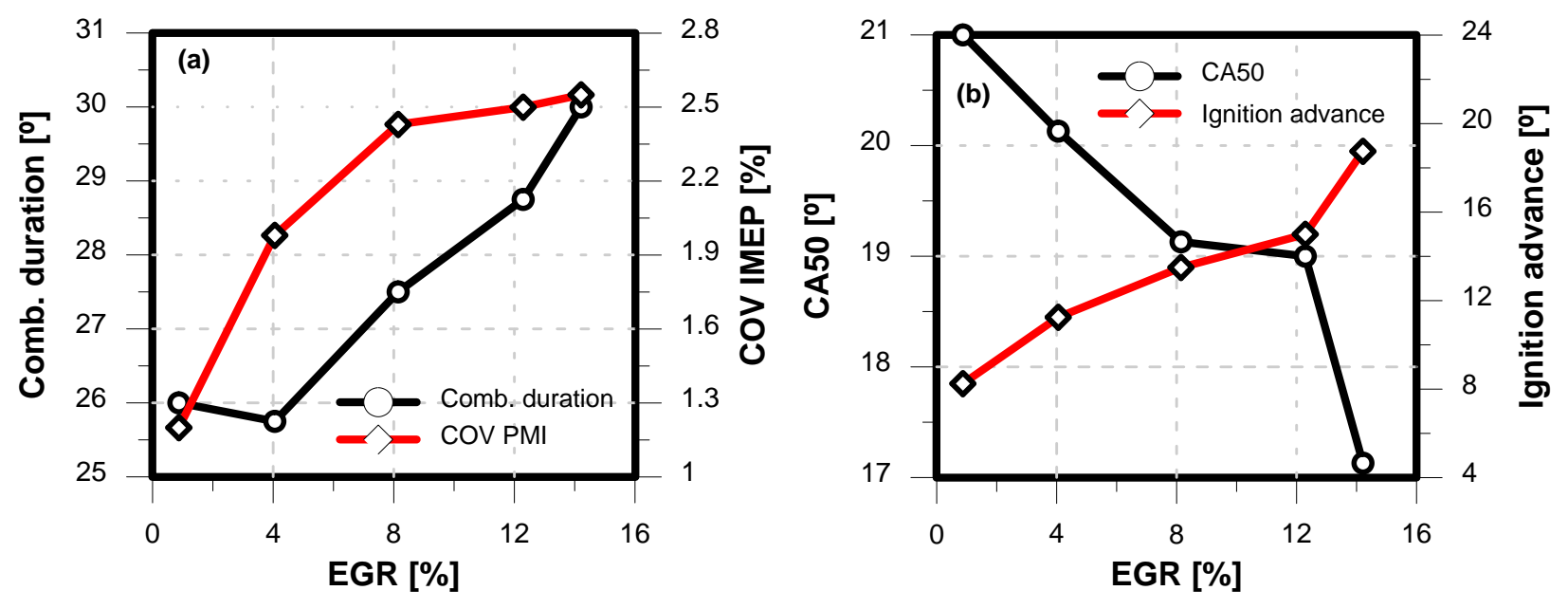

Figure 13. Combustion parameters variation for different EGR rates. (a) Combustion duration and CoV of the indicated mean effective pressure. (b) CA50 and ignition advance 

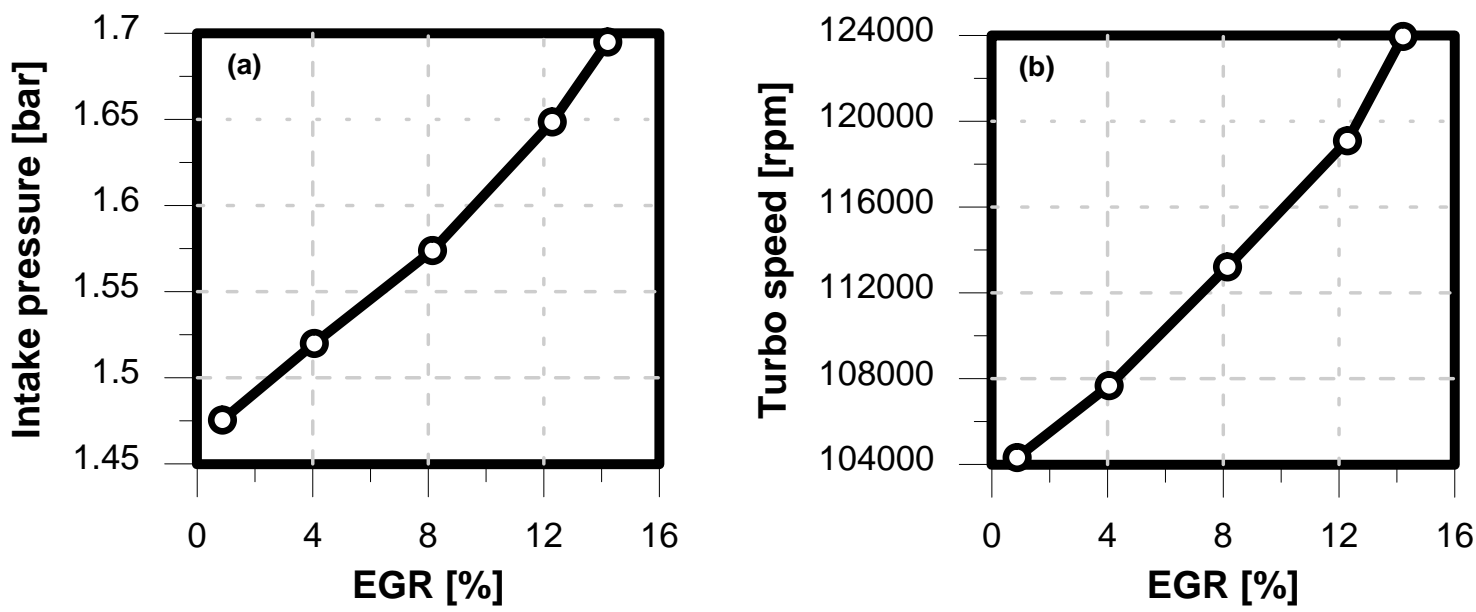

Figure 14. Air management parameters evolution for different EGR rates. (a) Intake pressure. (b) Turbocharger speed 

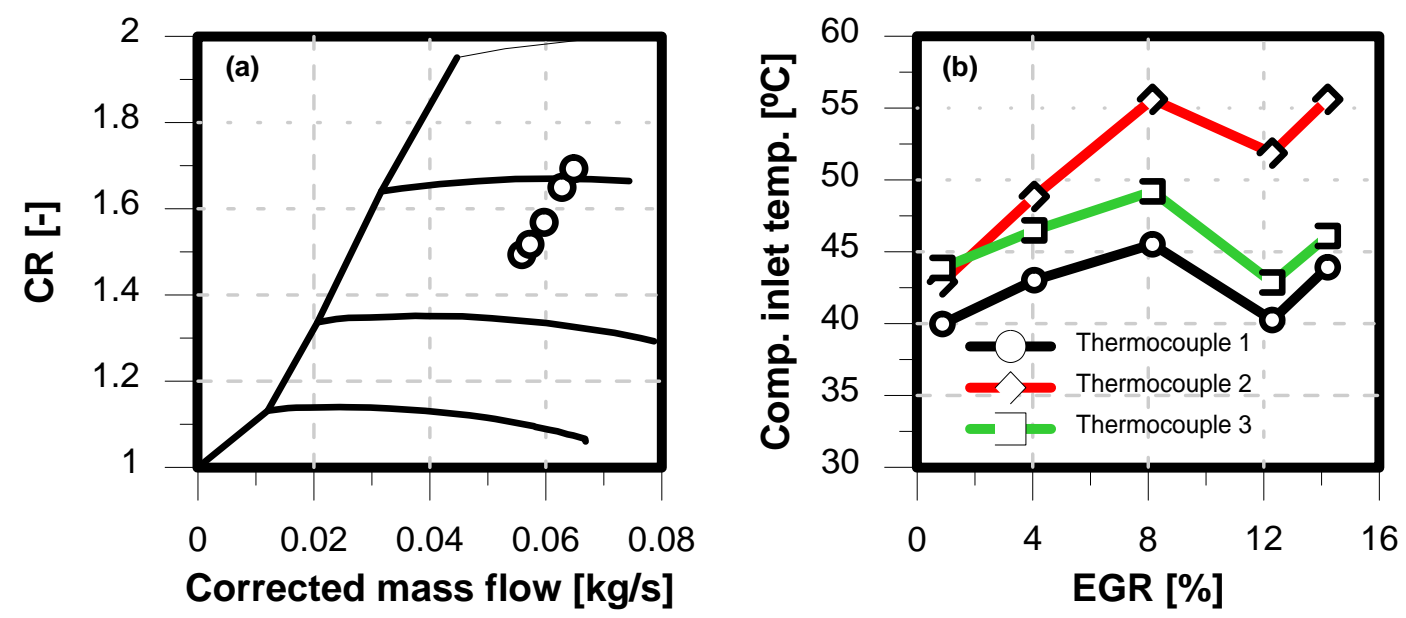

Figure 15. (a) Compressor operating points. (b) Compressor inlet temperature evolution for different EGR rates 

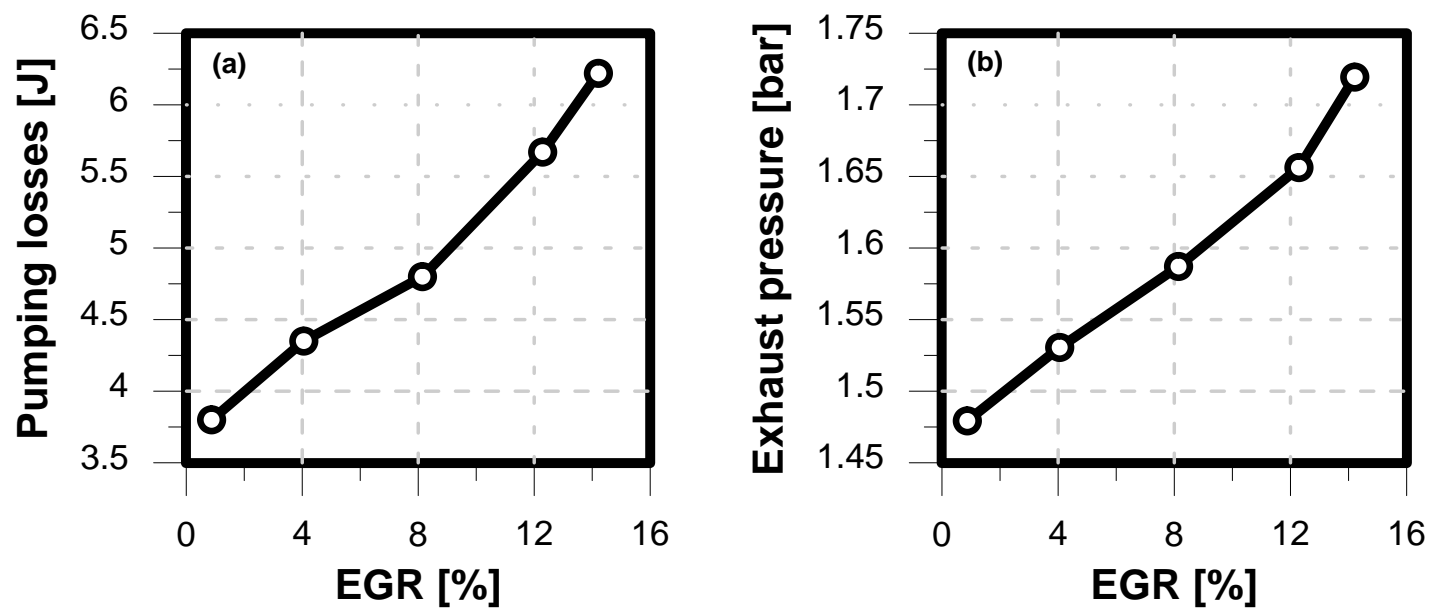

Figure 16. Air management parameters evolution for different EGR rates. (a) Pumping losses. (b) Exhaust manifold pressure 

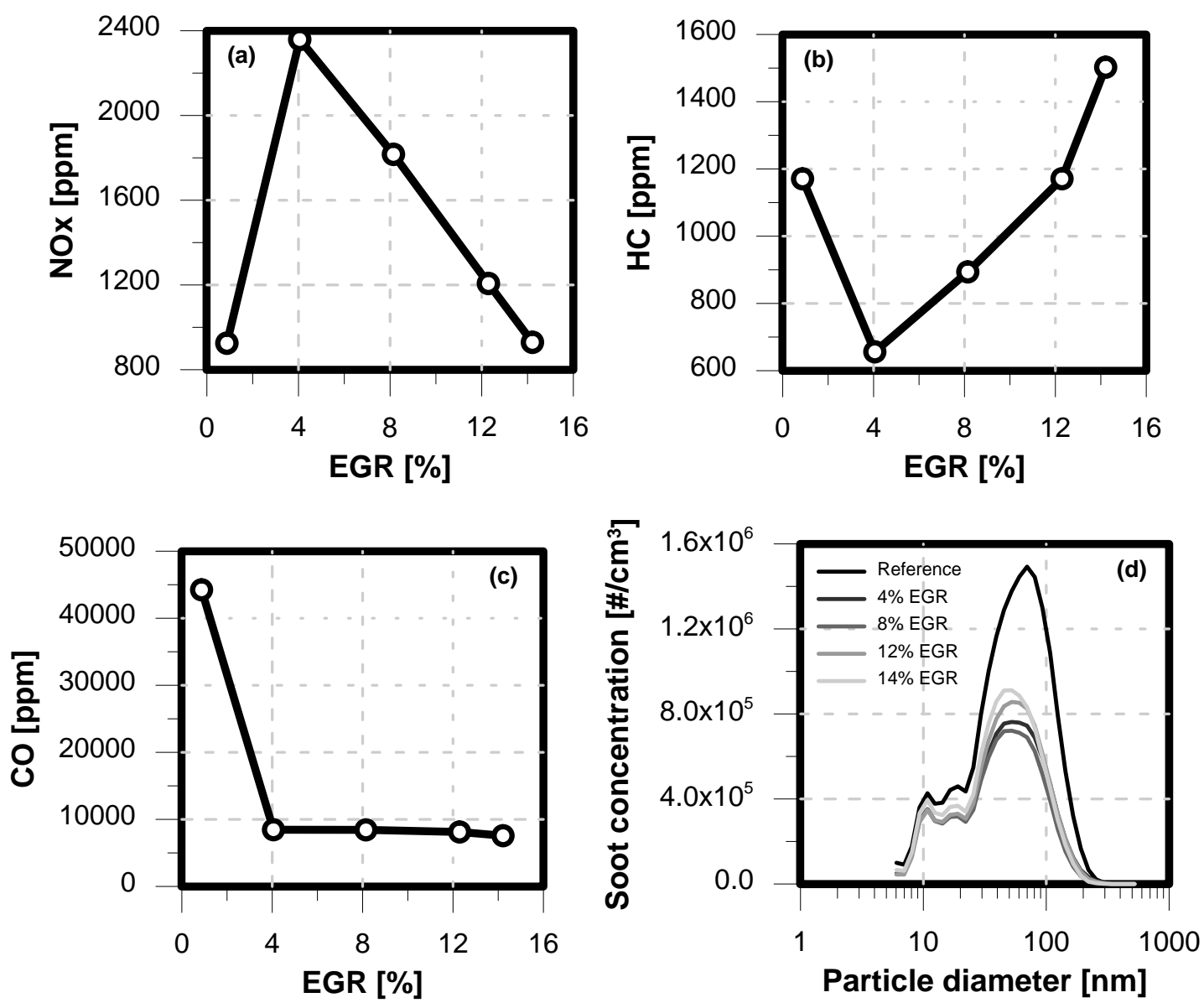

Figure 17. Exhaust emissions evolution for different EGR rates. (a) NOx. (b) HC. (c) CO. (d) Soot 